\title{
TURNOS ALTERNANTES: FADIGA MENTAL DE ENFERMAGEM*
}

\author{
Maria Helena Palucci Marziale ${ }^{\star \star}$ \\ Reinier Johanes Antonius Rozestraten ${ }^{\star \star \star}$
}

O objetivo do presente estudo foi detectar sintomas e sinais de fadiga mental, em enfermeiras atuantes em instituição hospitalar com esquema de trabalho em turnos alternantes, através de um indicador subjetivo "check-list" e dos indicadores objetivos Freqüência Crítica de Fusão da luz (Flicker) e Tempo de Reação simples a estímulo auditivo (TRs). Foram analisadas, 5 jornadas consecutivas trabalhadas nos turnos: manhã, tarde e noite por 12 enfermeiras de três unidades de internação diferentes de um hospital universitário. Os resultados sugerem que a alternância existente entre os turnos é prejudicial à saúde a à vida sócio - familiar e profissional dessas enfermeiras, as quais revelaram insatisfação pelo esquema de trabalho e apresentaram sintomas e sinais de fadiga mental. A incidência dos sintomas foi maior no turno da noite que no turno da manhã, a qual foi maior que a do turno da tarde quando comparados os valores obtidos no início e final dos turnos, evidenciando-se com maior freqüência os sintomas de embotamento e distúrbios do sono. Indícios de fadiga foram detectados através do Flicker na seguinte ordem: turno da manhã maior que o da noite, o qual foi maior que o da tarde, quando comparados os valores no início de final dos turnos. Em contrapartida, na verificação do tempo de Reação simples, os indícios de fadiga foram apresentados no turno da noite em freqüência maior que a do turno da manhã, o qual foi maior que a da tarde.

UNITERMOS: fadiga mental, turnos alternantes

\footnotetext{
*Este artigo foi extraído da dissertação de mestrado intitulada "Estudo da fadiga mental de enfermeiras atuantes em instituição hospitalar com esquema de trabalho em turnos alternantes", apresentada ao programa de pósgraduação de Psicobiologia da Faculdade de Filosofia Ciências e Letras de Ribeirão Preto -USP 1990 **Professor Assistente da Escola de Enfermagem de Ribeirão Preto -USP - Brasil

***Professor Titular da Faculdade de Filosofia, Ciências e Letras de Ribeirão Preto -USP - Brasil
} 
No Brasil de maneira geral a relação saúde-trabalho é muito problemática, devido especialmente a inexistência de condições de vida e trabalho satisfatórias. Essa precariedade pode ser detectada, dentre a várias determinações da referida relação, através da elevada incidência de acidentes de trabalho e doenças ocupacionais, mesmo que as notificações encontradas não coincidam coma realidade. Direcionando atenção a área de Enfermagem constata-se através da literatura LOPES (1988); POSSO (1988); MARZIALE et al (1991); AQUINO et al (1993), que seus profissionais possuem condições de trabalho insatisfatórias devido a inúmeros fatores que vão desde a baixa remuneração à esquemas de horários de trabalho adotados.

A atividade de Enfermagem é caracterizada pela promoção, manutenção e restabelecimento das necessidades básicas do indivíduo, em especial quando este é atingido em sua integridade física e/ou mental.

Atualmente no Brasil, essas atividades são realizadas por profissionais que se encontram subdivididos segundo preparo. São eles: enfermeiros, técnicos e auxiliares de Enfermagem e atendentes sendo que, essa última categoria não é regulamentada por lei (COFEn/ABEn, 1985).

No que diz respeito às enfermeiras****, POTTIER e ESTRYN-BEHAR (1979) assinalam que essa categoria profissional depara-se com uma série de dificuldades ocasionadas pela carga física e mental sofrida na prestação da assistência, pela alteração dos ritmos biológicos devido a constantes mudanças de turnos e ainda devido às condições de alimentação e transporte.

Especificamente em relação à carga mental, tem-se que a diversidade e a complexidade dos procedimentos técnicos, a hierarquização, a organização do trabalho e a confrontação cotidiana com o sofrimento, dor e morte são causadores de carga mental excessiva no trabalho das enfermeiras, os quais podem levar a fadiga.

Fadiga é um fenômeno preocupante da situação de trabalho de difícil conceituação, interpretação e aferição e que se torna complexo, porque serve para nomear um estado global resultante do desequilíbrio interno devido ao sistema de relações do organismo.

Entende-se após longa revisão da literatura, que a fadiga, pode atingir indivíduos de todas as faixas etárias, no desenvolvimento de qualquer tipo de atividade realizada por um período de tempo, que além de ser um fenômeno que causa mal estar, provoca alterações no estado psicossomático, podendo ser encarado como resultante de esforço físico e/ou mental associado às condições do ambiente, fatores psicológicos inerentes ao regime de trabalho, condições individuais e as condições de trabalho.

\footnotetext{
${ }^{\star * \star \star}$ Optou-se neste estudo pela utilização do gênero feminino para nomear a enfermeira, uma vez que $94,1 \%$ desses profissionais são do sexo feminino (COFEn/ABEn, 1985)
} 
Segundo WISNER (1987) toda situação de trabalho tem pelo menos três aspectos; físico cognitivo e psíquico e cada um deles pode determinar uma sobrecarga.

O trabalho se toma perigoso ao aparelho psíquico tão logo ele se oponha a sua livre atividade. Cada indivíduo possui suas formas de descargas preferenciais; a satisfação e o prazer no trabalho são potentes formas de descargas psíquicas.

Se um trabalhador permite a diminuição da carga psíquica, ele está em equilíbrio; no inverso ocorre sobrecarga devido ao acúmulo de energia levando a um estado de tensão e desprazer, conseqüentemente propiciando o aparecimento da fadiga mental.

A fadiga mental pode ser originada pelo inter-relacionamento de fatores profissionais e/ou extraprofissionais e as características do indivíduo. Entre os fatores pode-se ressaltar: iluminação inadequada, desconforto térmico, sonoro, pausas insuficientes, jornadas prolongadas esquemas de turnos, vícios posturais, trabalho monótono e repetitivo, mau relacionamento, responsabilidade, salário, alta concentração mental e ambiente de trabalho estressante, baixo padrão de vida, problemas de alimentação, habitação, vestuário, transporte, assistência social e médica (ESPOSITO et al 1980).

O indivíduo reage aos agentes estressantes de acordo com sua constituição e sua maneira de conceber o mundo. Assim, para que ocorra adaptação entre o indivíduo e seu trabalho, existe a necessidade de analisar os fatores ora descritos, a fim de evitar-se a fadiga.

COUTO (1978), aponta como principais sintomas da fadiga psíquica: cefaléia, adinamia, alterações do sono, angústia, ansiedade, dificuldade para respiração profunda, dores gerais e precordiais, palpitações, vertigens, sudorese, diarréia, diminuição da memória, cansaço fácil, tendência a hipocondria, alterações visuais, humor deprimido e diminuição da libido. E ressalta que ela pode ser também considerada em relação ao tipo de duração da manifestação, ou seja, pode ser aguda e crônica.

Diante da complexidade do fenômeno da fadiga e suas repercussões na execução do trabalho, buscou-se estudar a relação existente entre turnos alternantes e sinais e sintomas de fadiga mental em enfermeiras.

\section{OBJETIVOS}

Os objetivos propostos para essa pesquisa foram:

Detectar, através de indicadores subjetivos sintomas de fadiga mental em enfermeiras atuantes em um hospital de ensino, que utilizava o esquema de trabalho em turnos alternantes.

Detectar, através de indicadores objetivos, sinais de fadiga mental em enfermeiras atuantes em um hospital de ensino que utilizava o esquema de trabalho em turnos alternantes. 


\section{METODOLOGIA}

Considerou-se como universo deste estudo as enfermeiras lotadas nas unidades de internação das clínicas médica, cirúrgica e ginecológica do hospital universitário da cidade de Ribeirão Preto, São Paulo - Brasil.

Estabeleceu-se os seguintes requisitos para composição da amostra: enfermeiras não ocupantes de cargo de chefia e que concordassem em participar do estudo. A amostra foi composta por 12 sujeitos sendo: 4 enfermeiras lotadas na unidade de clínica médica, 4 na clínica cirúrgica e 4 na clínica de ginecologia.

Com relação à dinâmica dos turnos de trabalho esses possuíam: 6:10 horas de duração nos plantões da manhã e tarde e 12:00 horas no turno da noite. Ressalta-se que após o trabalho no período noturno as enfermeiras possuíam 36:00 horas de período de descanso e de modo geral trabalhavam no máximo 7 dias consecutivos.

Os turnos seguiam os seguintes horários: manhã das 07:00 às 13:10 horas, tarde das 13:00 às 19:10 horas e noite das 19:00 às 07:00 horas. Havendo período de pausa de 15 minutos nos turnos manhã e tarde e de 40 minutos no turno noturno.

Foram usadas as seguintes abordagens metodológicas neste estudo:

- Observacional: utilizada para a caracterização das atividades desenvolvidas pelas enfermeiras. Observações cursivas foram realizadas por três monitores e pelo autor deste estudo após serem submetidos a treinamento prévio, sendo empregado para o cálculo do índice de fidedignidade entre as observações a fórmula proposta por BIJU usada por CARVALHO (1979) considerando-se satisfatório o índice de fidedignidade igual a 0,85.

Foram observadas, as atividades realizadas por uma enfermeira durante toda sua jornada de trabalho em cada um dos turnos nas três unidades de internação estudadas.

Para registro das observações utilizou-se uma ficha contendo dados de identificação do sujeito, espaço para registro das atividades realizadas e do tempo gasto para execução das mesmas. O tempo foi computado através do uso de cronômetro com leitura inicialmente feita em segundos e posteriormente transformados em minutos.

- Questionário e escala de avaliação de diferencial semântico: usados para obter informações da vida sócio-profissional e familiar das enfermeiras e do esquema de trabalho.

- "Check-list": utilizado para detecção de sintomas subjetivos de fadiga. Foi composto por 36 sintomas estudados pelo Comitê de pesquisa em fadiga industrial da Associação Japonesa de Saúde Industrial, descritos por YOSHITAKE (1978), mesclados a 13 sintomas opostos a fadiga mental. Sendo então agrupados:

10 sintomas relativos a inabilidade de concentração, 13 sintomas relacionados a embotamento e distúrbio do sono, 13 sintomas relativos ao padrão de desconforto físico e 13 sintomas opostos a presença de fadiga. O "Check-list" foi aplicado no inicio e no término de cada turno durante 15 dias consecutivos.

- Experimental: usada para detectar sinais objetivos de fadiga mental, através da aferição da freqüência critica de fusão da luz (Flicker) e do Tempo de Reação simples à estímulo auditivo (TRs). Ambos aplicados no início e término dos turnos. 
O Flicker é um dos mais utilizados indicadores objetivos da fadiga mental, mede o reflexo das variações do grau de ativação cortical do indivíduo e é também uma medida do estado de equilíbrio do sistema nervoso central, os quais são modificados pela fadiga. Quanto mais fatigado o sujeito menor será o grau de ativação cortical.

O TRs também é um indicador muito usado para detecção de sinais de fadiga mental, mede a excitação sensorial a estímulos auditivos ou visuais. Quanto mais fadigado o sujeito, mais lenta será a resposta emitida ao estimulo.

Para análise dos dados empregou-se o cálculo de freqüência percentual, médias, teste de Friedman, e qui-quadrado.

\section{RESULTADOS E DISCUSSÃO}

Diversas eram as atividades desenvolvidas pelas enfermeiras no hospital estudado. Para análise optou-se pela categorização das mesmas em três grupos:

prestação de assistência direta e indireta ao paciente e outras atividades.

Observou-se que nos turnos manhã e tarde, as atividades desenvolvidas eram voltadas de maneira semelhante a prestação de cuidados diretos e indiretos e no turno da noite havia predomínio do cuidado direto.

A rotina do turno da manhã foi caracterizada pela execução de cuidados de higiene, curativos, coleta de materiais para exames, requisição de materiais e medicamentos, avaliação clínica de clientes, encaminhamentos para exames e cirurgias. Durante a tarde foram freqüentes os procedimentos relativos à internação e alta hospitalar, preparo para exames e cirurgias, recepção pós-operatória, visita de familiares e esporadicamente reuniões com funcionários.

No turno da noite foram características as atividades de recepção pós-operatória, revisão de prontuários e manutenção de cuidados, sendo relevante a redução do número de atividades e de funcionários em relação aos outros turnos.

Além da prestação de assistência direta ao cliente, a enfermeira era responsável pela supervisão de funcionários, organização da unidade e era a intermediária entre o cliente e o médico, atuando ainda também na administração da unidade.

A realização de todas essas atividades acrescidas do grande número de interrupções durante o trabalho e de fatores inerentes ao ambiente hospitalar faz com que seu trabalho seja considerado mentalmente desgastante.

No período em que os dados foram coletados as enfermeiras trabalharam 107 jornadas entre as quais 44 no turno da manhã, 34 no turno da tarde e 29 no turno da noite. Devido à distribuição dos mesmos não ocorrer de forma eqüitativa, optou-se pela análise estatística não paramétrica dos dados, o que possibilitou de maneira satisfatória a análise dos resultados obtidos.

A amostra foi composta por 12 enfermeiras com idade variando entre 20 e 40 anos, sendo $58,0 \%$ delas solteiras e $42,0 \%$ casadas, $67,0 \%$ delas possuindo tempo de serviço de seis anos no esquema de turnos alternantes. 
Em relação ao esquema alimentar, observou-se que $83,2 \%$ das enfermeiras tinham esquema alimentar composto por refeições irregulares e $41,6 \%$ delas substituíam suas refeições por lanches. Esses achados vão de encontro à afirmação feita por GENAILLE (1990) de que, as refeições das enfermeiras raramente são consumidas dentro dos horários normais reservados para alimentação.

Obteve-se que $83,3 \%$ das enfermeiras apontaram o esquema de trabalho em turnos alternantes como fator de influência negativa aos aspectos de relacionamento familiar, social com o lazer e o sono.

Conforme o relato de GOMES (1986), uma característica importante no grupo profissional das enfermeiras é o grande contingente feminino, sendo portanto, oportuno considerar as inúmeras obrigações que ela possui perante a família e a sociedade quando se estuda suas relações de trabalho.

Os efeitos do trabalho em turnos na vida conjugal têm sido relatado como fator que provoca mais tensão no casamento, ou ao contrário, devido a problemas conjugais leva o sujeito a aceitar o trabalho no referido esquema.

O trabalho realizado em turnos alternantes e a vida social da enfermeira é prejudicado, segundo relato de ESTRYN BEHAR (1980), principalmente nos finais de semana, onde a família e os amigos vão ao clube, a restaurantes, a cinemas e a enfermeira, mãe, esposa, amiga, vai para o trabalho.

DUMAZEDIER (1973) afirma ser o lazer um fator reparador das deteriorações físicas e mentais provocadas pelas tensões cotidianas e do trabalho sendo extremamente necessário.

Segundo $75,0 \%$ das enfermeiras, o esquema de trabalho em turnos alternantes era prejudicial ao lazer, entretanto $25,0 \%$ das enfermeiras apontaram não haver interferência na referida relação.

A relação entre turnos alternantes e o sono também foi analisada, sendo observado que $91,7 \%$ dos sujeitos julgaram que esse esquema de trabalho interfere negativamente no sono.

Questionou-se, a respeito do número de horas dormidas a cada 24 horas e obtevese como resposta uma média de 6:30 horas. Entretanto, muitas enfermeiras relataram não apresentar uma boa qualidade de sono, devido a interrupções no sono e dificuldades de dormir durante o dia.

Segundo DESCHAMPS e CREPY (1989), a mudança forçada do horário de dormir pela alternância dos turnos diurnos e noturnos, reduz o tempo de sono, pois dormir durante o dia é extremamente desfavorável devido a não adaptação dos ritmos biológicos e a inversão do trabalho noturno e repouso diurno. Isso faz com que a qualidade do sono não seja boa, fator importante para obtenção de descanso satisfatório.

Os referidos autores consideram ainda que o trabalho em horários alternantes pode levar a perturbações qualitativas do sono, sobretudo na duração de suas fases e na profundidade. O sono diurno possui características diferentes do sono noturno devido a elementos sociais, ambientais e fatores intrínsecos como as variações cíclicas do organismo. 
Para obtenção de bom desempenho, a pessoa deve começar a trabalhar descansada. O cansaço impede o bom rendimento físico, diminui o nível de atenção e perturba sensivelmente a coordenação motora e o ritmo mental. Por isso, segundo RUTENFRANZ et al. (1989), o sono e o descanso adquirem importância especial para o trabalhador em turnos.

Observou-se que $41,6 \%$ dos sujeitos referiram ter outras atividades de cunho empregatício, principalmente na área comercial e de ensino, enquanto 58,4\% apontaram realizar atividades domésticas. Essa atividade foi considerada por 50,0\% das enfermeiras como trabalho "pesado" e por 33,3\% como trabalho "moderado".

O trabalho no hospital foi julgado por 58,3\% das enfermeiras como "cansativo".

Com relação a satisfação pelo trabalho em esquema de turnos alternantes, observou-se que $75,0 \%$ das enfermeiras não estavam satisfeitas pelo fato do esquema adotado interferir negativamente na vida social e familiar, no sono, na alimentação e proporcionar-Ihes desgaste físico e mental. No entanto, 25,0\% das enfermeiras responderam que estavam satisfeitas por não gostarem de rotinas e pelo esquema adotado permitir oportunidade de conhecer as atividades executadas em todos os turnos.

Com relação ao melhor horário para trabalhar $58,3 \%$ das enfermeiras optaram pelo turno da manhã, 41,6\% pelo turno da tarde e nenhuma enfermeira apontou o turno da noite.

Quanto ao tipo de trabalho realizado e a propensão à fadiga, 75,0\% das enfermeiras julgaram que o trabalho poderia levá-las à fadiga, 8,3\% das enfermeiras optaram pela neutralidade e $16,6 \%$ apontaram ser difícil o aparecimento da fadiga.

Segundo CAMERON (1973), muitos autores consideram o índice de acidentes de trabalho como indicador de fadiga. Averiguando-se essa variável observou-se que 41,6\% das enfermeiras já haviam sofrido acidentes de trabalho. Dessas, 25,0\% haviam sofrido mais de um acidente de trabalho, principalmente lesões corto-perfurantes e contato com material contaminado.

Os motivos alegados pelas enfermeiras da amostra estudada em relação a ocorrência dos acidentes foram distração, pressa e excesso de trabalho. Das enfermeiras acidentadas $20,0 \%$ julgaram que o esquema de trabalho em turnos alternantes possa ter contribuído na ocorrência do acidente.

Segundo FISCHER (1985), o esquema dos turnos de trabalho é uma variável que intervém na ocorrência dos acidentes de trabalho, enquanto LAURENTI (1975) chama atenção para o fato de que o acidente de trabalho permite avaliar a adequacidade entre o homem e o ambiente de trabalho, bem como o grau de deterioração de tal equilíbrio.

A tabela 1 apresenta os resultados obtidos através da aplicação do "Checklist", cujo objetivo foi detectar os sintomas subjetivos da fadiga. 
Tabela 1 - Distribuição dos sintomas subjetivos da fadiga mediante categorização segundo turno e período de trabalho emitidos por 12 enfermeiras, Ribeirão Preto - SP Brasil

\begin{tabular}{|c|c|c|c|c|c|c|c|c|}
\hline & \multirow{2}{*}{$\begin{array}{l}\text { Turno } \\
\text { Sintomas }\end{array}$} & \multicolumn{2}{|c|}{$\begin{array}{c}\text { N: } 44 \\
\text { Manhã }\end{array}$} & \multicolumn{2}{|c|}{$\begin{array}{l}\mathrm{N}: 44 \\
\text { Tarde }\end{array}$} & \multicolumn{2}{|c|}{$\begin{array}{l}\text { N: } 44 \\
\text { Noite }\end{array}$} & \multirow{2}{*}{$\begin{array}{c}\text { TOTAL } \\
\mathrm{N}^{\circ}\end{array}$} \\
\hline & & $\begin{array}{c}\text { início } \\
\text { N. }\end{array}$ & $\begin{array}{c}\text { final } \\
\text { N. }\end{array}$ & $\begin{array}{c}\text { início } \\
\text { N. }\end{array}$ & $\begin{array}{l}\text { final } \\
\text { N. }\end{array}$ & $\begin{array}{c}\text { início } \\
\text { N. }{ }^{\circ}\end{array}$ & $\begin{array}{c}\text { Final } \\
\text { N.o }\end{array}$ & \\
\hline \multirow[t]{2}{*}{ I } & $\begin{array}{l}\text { - Dificuldade de pensar } \\
\text { - Irritabilidade } \\
\text { - Inquietação } \\
\text { - Dificuldade de concentrar a atenção } \\
\text { - Desinteresse pelas coisas } \\
\text { - Insegurança nas ações realizadas } \\
\text { - Sensação de cometer erros } \\
\text { - Sensação de esquecimento } \\
\text { - Cabeça "quente" }\end{array}$ & $\begin{array}{l}7 \\
8 \\
6 \\
5 \\
3 \\
3 \\
3 \\
7 \\
5\end{array}$ & $\begin{array}{c}18 \\
18 \\
12 \\
17 \\
6 \\
4 \\
4 \\
16 \\
25\end{array}$ & $\begin{array}{l}- \\
5 \\
8 \\
4 \\
2 \\
- \\
- \\
1 \\
1\end{array}$ & $\begin{array}{c}5 \\
6 \\
14 \\
8 \\
2 \\
- \\
- \\
10 \\
7\end{array}$ & $\begin{array}{c}4 \\
6 \\
12 \\
2 \\
7 \\
- \\
1 \\
5 \\
4\end{array}$ & $\begin{array}{c}17 \\
18 \\
3 \\
18 \\
12 \\
4 \\
10 \\
20 \\
15\end{array}$ & $\begin{array}{l}51 \\
61 \\
55 \\
54 \\
32 \\
11 \\
38 \\
59 \\
57\end{array}$ \\
\hline & Subtotal & 47 & 140 & 21 & 52 & 41 & 117 & 418 \\
\hline \multirow[t]{2}{*}{ II } & $\begin{array}{l}\text { - Cabeça pesada } \\
\text { - Vontade de bocejar freqüente } \\
\text { - Sensação de confusão mental } \\
\text { - Sonolência } \\
\text { - Olhos ardendo } \\
\text { - Vontade de dormir } \\
\text { - Vontade de deitar } \\
\text { - Sem vontade de falar } \\
\text { - Ansiedade } \\
\text { - Nervosismo } \\
\text { - Desânimo } \\
\text { - Angústia } \\
\text { - Impaciência }\end{array}$ & $\begin{array}{c}9 \\
8 \\
4 \\
16 \\
13 \\
5 \\
7 \\
3 \\
7 \\
5 \\
22 \\
3 \\
8\end{array}$ & $\begin{array}{c}25 \\
11 \\
11 \\
6 \\
22 \\
11 \\
15 \\
5 \\
8 \\
16 \\
14 \\
4 \\
23\end{array}$ & $\begin{array}{c}4 \\
2 \\
- \\
3 \\
10 \\
2 \\
1 \\
2 \\
12 \\
3 \\
6 \\
4 \\
4\end{array}$ & $\begin{array}{c}8 \\
3 \\
1 \\
2 \\
12 \\
5 \\
18 \\
3 \\
5 \\
2 \\
7 \\
6 \\
19\end{array}$ & $\begin{array}{c}3 \\
3 \\
2 \\
4 \\
14 \\
7 \\
7 \\
3 \\
8 \\
8 \\
9 \\
2 \\
15\end{array}$ & $\begin{array}{l}17 \\
23 \\
18 \\
25 \\
27 \\
29 \\
24 \\
13 \\
4 \\
1 \\
7 \\
2 \\
20\end{array}$ & $\begin{array}{l}66 \\
50 \\
36 \\
56 \\
98 \\
59 \\
72 \\
29 \\
44 \\
35 \\
65 \\
24 \\
39\end{array}$ \\
\hline & Subtotal & 110 & 171 & 53 & 91 & 85 & 210 & 720 \\
\hline \multirow[t]{3}{*}{ III } & $\begin{array}{l}\text { - Sensação de peso nos ombros } \\
\text { - Corpo cansado } \\
\text { - Cefaléia } \\
\text { - Dores nas costas } \\
\text { - Palpitação } \\
\text { - Opressão na respiração } \\
\text { - Dor no estômago } \\
\text { - Voz rouca } \\
\text { - Tremores nas pálpebras } \\
\text { - Tremores nos membros } \\
\text { - Mal estar } \\
\text { - Corpo tornou-se rígido para } \\
\text { movimentar-se } \\
\text { - Cansaço nas pernas }\end{array}$ & $\begin{array}{c}7 \\
18 \\
10 \\
7 \\
3 \\
4 \\
3 \\
6 \\
2 \\
6 \\
7 \\
5 \\
12\end{array}$ & $\begin{array}{c}9 \\
23 \\
8 \\
19 \\
- \\
5 \\
3 \\
5 \\
1 \\
4 \\
8 \\
3 \\
26\end{array}$ & $\begin{array}{c}2 \\
10 \\
1 \\
7 \\
1 \\
4 \\
1 \\
2 \\
- \\
1 \\
2 \\
- \\
14\end{array}$ & $\begin{array}{c}8 \\
19 \\
3 \\
8 \\
1 \\
5 \\
3 \\
1 \\
3 \\
6 \\
1 \\
- \\
23\end{array}$ & $\begin{array}{c}4 \\
24 \\
3 \\
9 \\
1 \\
1 \\
- \\
3 \\
1 \\
3 \\
1 \\
1 \\
20\end{array}$ & $\begin{array}{c}5 \\
29 \\
3 \\
17 \\
1 \\
- \\
4 \\
2 \\
1 \\
2 \\
4 \\
3 \\
26\end{array}$ & $\begin{array}{c}35 \\
123 \\
28 \\
67 \\
7 \\
19 \\
14 \\
19 \\
8 \\
22 \\
23 \\
12 \\
121\end{array}$ \\
\hline & Subtotal & 96 & 114 & 45 & 81 & 71 & 97 & 498 \\
\hline & Total & 247 & 425 & 119 & 224 & 197 & 424 & 1636 \\
\hline
\end{tabular}

Categoria I - Sintomas relativos a inabilidade de concentração Categoria II - Sintomas relativos a embotamento e distúrbios do sono Categoria III - Sintomas relativos a desconforto físico 
Analisaram-se as possíveis diferenças existentes na incidência dos sintomas apontados através da categorização empregada, no início e final dos períodos de trabalho nos turnos, manhã, tarde e noite. Utilizou-se o teste de Friedman (apud HOLLANDER e WOLFE, 1973) como recurso para análise estatística dos dados.

As hipóteses utilizadas foram:

$\mathrm{H}_{0}$ : as enfermeiras iniciavam e terminavam seus turnos de trabalho de forma idêntica quando analisados os sintomas subjetivos da fadiga.

$\mathrm{H}_{1}$ : existiam diferenças entre o início e final dos turnos de trabalho em relação ao apontamento de sintomas subjetivos da fadiga feito pelas enfermeiras.

Os valores encontrados referente aos sintomas pertencentes à categoria 1, apontaram a não existência diferenças significativas relativas à incidência de sintomas de inabilidade de concentração, quer no início ou final dos três turnos de trabalho.

Em relação aos valores encontrados na categoria II, obteve-se que não houve diferenças significativas no início dos turnos quanto a incidência dos sintomas relativos a embotamento e distúrbios do sono. No entanto, no final dos referidos turnos observou-se a existência de diferenças significativas.

Diante da rejeição de $\mathrm{H}_{0}$, efetuou-se as comparações múltiplas pelo teste de Friedman dois a dois, obtendo-se que os sintomas do período da noite diferia significativamente os do período da tarde.

Constatou-se através dos sintomas apresentados na tabela 1 que a incidência dos sintomas de embotamento e distúrbios do sono se deu na seguinte ordem: turno da noite>manhã $>$ tarde.

Quanto a categoria III, padrão de desconforto físico, foram encontradas diferenças significativas no início dos turnos manhã, tarde e noite. Encontrou-se que a incidência de sintomas do período da tarde. Os sintomas foram apontados na seguinte ordem: turno da noite $>$ manhã $>$ tarde.

A tabela 2 apresenta os resultados obtidos quanto a incidência dos sintomas opostos à fadiga agrupados na categoria IV. Esses foram apontados de maneira diferente, no início e no final dos turnos, sendo incidentes na seguinte ordem: turno tarde>noite>manhã. 
Tabela 2 - Distribuição dos sintomas subjetivos opostos à sensação de fadiga, segundo turno e período de trabalho emitido por 12 enfermeiras, Ribeirão Preto - SP Brasil

\begin{tabular}{|c|c|c|c|c|c|c|c|c|}
\hline \multirow{2}{*}{\multicolumn{2}{|c|}{$\begin{array}{l}\text { Turno } \\
\text { Sintomas }\end{array}$}} & \multicolumn{2}{|c|}{$\begin{array}{c}\text { N: } 44 \\
\text { Manhã }\end{array}$} & \multicolumn{2}{|c|}{$\begin{array}{l}\mathrm{N}: 44 \\
\text { Tarde }\end{array}$} & \multicolumn{2}{|c|}{$\begin{array}{l}\text { N: } 44 \\
\text { Noite }\end{array}$} & \multirow{2}{*}{$\begin{array}{c}\text { TOTAL } \\
\text { N. }^{\circ}\end{array}$} \\
\hline & & $\begin{array}{c}\text { Início } \\
\text { N.o }\end{array}$ & $\begin{array}{l}\text { final } \\
\mathrm{N}^{\circ}\end{array}$ & $\begin{array}{c}\text { início } \\
\text { N. }{ }^{\circ}\end{array}$ & $\begin{array}{l}\text { final } \\
\text { N. }\end{array}$ & $\begin{array}{c}\text { início } \\
\text { N. }\end{array}$ & $\begin{array}{l}\text { Final } \\
\text { N. }\end{array}$ & \\
\hline & - Bem-estar geral & 19 & 6 & 27 & 11 & 21 & 5 & 89 \\
\hline & - Atividade & 18 & 8 & 26 & 19 & 23 & 4 & 98 \\
\hline & - Ânimo & 13 & 4 & 22 & 13 & 17 & 3 & 72 \\
\hline & - Calma & 30 & 16 & 25 & 19 & 20 & 13 & 123 \\
\hline & - Sem vontade de falar conversar & 2 & 4 & 10 & 8 & 3 & 3 & 30 \\
\hline & - Paciência & 11 & 6 & 8 & 11 & 9 & 5 & 50 \\
\hline IV & - Bom humor & 19 & 11 & 19 & 11 & 15 & 8 & 83 \\
\hline & - Segurança nas ações realizadas & 25 & 21 & 26 & 12 & 12 & 12 & 108 \\
\hline & - Sente-se "leve" & 6 & 4 & 7 & 3 & 7 & - & 27 \\
\hline & - Satisfação & 8 & 11 & 14 & 5 & 7 & 6 & 51 \\
\hline & - Felicidade & 6 & 3 & 12 & 1 & 3 & 1 & 26 \\
\hline & $\begin{array}{l}\text { - Sente-se com muita energia para } \\
\text { o trabalho }\end{array}$ & 10 & 3 & 19 & 6 & 17 & 2 & 57 \\
\hline & - Contentamento & 9 & 4 & 14 & 8 & 10 & 5 & 50 \\
\hline & Subtotal & 176 & 101 & 229 & 127 & 164 & 67 & 864 \\
\hline
\end{tabular}

Tais variações apontam existência de diferenças significativas entre os turnos tarde e noite e de que os sintomas opostos à sensação de fadiga foram apontados na ordem: turno da tarde>manhã $>$ noite.

Em relação aos resultados obtidos através do uso de indicadores objetivos, elaborouse os seguintes histogramas. 
Figura 1 - Variação das médias individuais do Flicker relativos ao início e ao final dos turnos da manhã, trabalhados durante quinze dias por 12 enfermeiras, Ribeirão Preto SP - Brasil

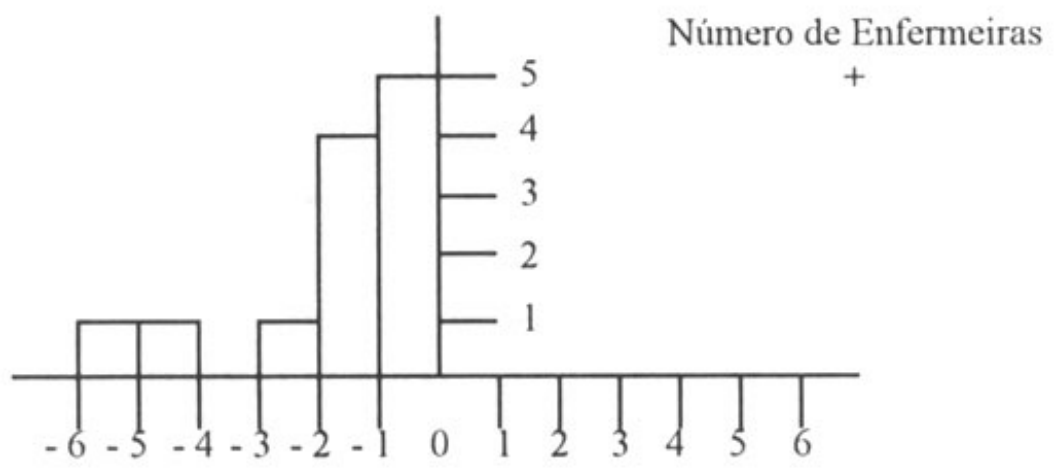

Variação das médias individuais do Flicker $(\mathrm{Hz})$

A figura 1 mostra a variação das médias individuais do Flicker entre o início e o final dos turnos da manhã, os resultados apontam que $41,6 \%$ das enfermeiras obtiveram um decréscimo de até $1,0 \mathrm{~Hz}$ no final do turno da manhã, em 33,3\% das enfermeiras esse decréscimo foi estabelecido entre 1,0 e $2,0 \mathrm{~Hz}$ 8,3\% das enfermeiras apresentaram decréscimos compreendidos entre 4,0 e $5,0 \mathrm{~Hz}$ e 8,3\% apresentaram decréscimo entre 5,0 e $6,0 \mathrm{~Hz}$. Observou-se ainda que $8,3 \%$ das enfermeiras não obtiveram variações de Flicker e nenhuma enfermeira obteve aumento da freqüência Flicker no turno da manhã.

Esses resultados indicam que ao final do turno da manhã 100,0\% das enfermeiras apresentaram valores da freqüência crítica de fusão da luz menores que os valores obtidos no início do referido turno, caracterizando assim, indícios de fadiga mental.

Segundo MUELLER (1966), a capacidade de detectar a alteração temporal a um estímulo visual que está repetidamente mudando de claro para escuro e outra vez claro (freqüência de intermitência) torna-se mais difícil à medida que o cansaço se instala, ou seja, o sujeito fatigado apresenta uma resolução temporal fraca, um Flicker com valores baixos.

As variações obtidas entre o início e o fim do turno da tarde encontram-se ilustradas na figura 2. 
Figura 2 - Variação das médias individuais do Flicker relativos ao início e ao final dos turnos da manhã, trabalhados durante quinze dias por 12 enfermeiras, Ribeirão Preto SP - Brasil

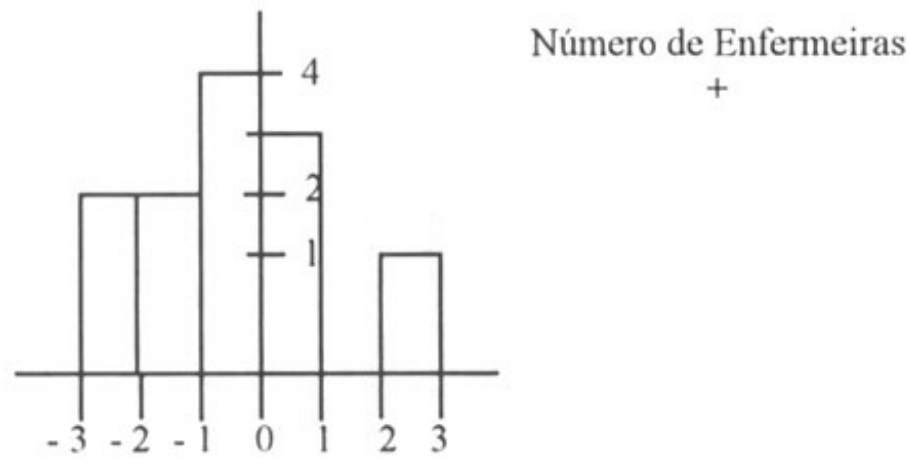

Variação das médias individuais do Flicker $(\mathrm{Hz})$

No turno da tarde $33,3 \%$ das enfermeiras obtiveram decréscimos nas médias do Flicker de até 1,0 Hz. Em 16,6\% das enfermeiras esse decréscimo foi estabelecido entre 1,0 e $2,0 \mathrm{~Hz}$ e em $16,6 \%$ foi entre 2,0 e $3,0 \mathrm{~Hz}$. No entanto, observou-se também que $33,3 \%$ das enfermeiras obtiveram aumento nos valores médios de suas respostas ao Flicker entre o início e o final do turno, sendo que $25,0 \%$ delas apresentaram um acréscimo de até 1,0 $\mathrm{Hz}$, e em $8,3 \%$ delas valores compreendidos entre 2,0 e 3,0 Hz.

Os dados referentes às variações ocorridas entre o inicio e o final do turno da noite são apresentados na figura 3.

Figura 3 - Variação das médias do Flicker relativos ao início e ao final dos turnos da noite trabalhados durante quinze dias por 12 enfermeiras, Ribeirão Preto - SP - Brasil

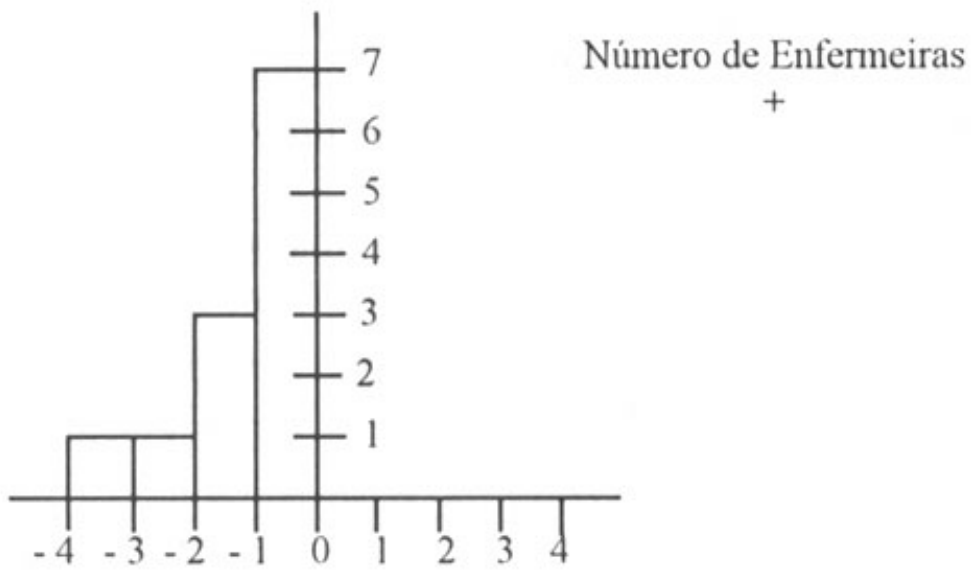

Variação das médias individuais do Flicker $(\mathrm{Hz})$ 
No turno da noite $58,4 \%$ das enfermeiras apresentaram decréscimos de até $1,0 \mathrm{~Hz}$, $25,0 \%$ das enfermeiras apresentaram decréscimos estabelecido entre 1,0 e 2,0 Hz, 8,3\% das enfermeiras apresentaram decréscimos entre 2,0 e $3,0 \mathrm{~Hz}$ e 8,3\% das enfermeiras entre 3,0 e $4,0 \mathrm{~Hz}$.

MATSUMOTO et al (1978), em estudo realizado com enfermeiras atuantes em unidades de internação e ambulatorial de um hospital geral de Kyorin no Japão, que se utilizava do esquema de turnos alternantes, constatou as variações do Flicker no turno da manhã variando no intervalo compreendido entre $-1,0 \mathrm{~Hz}$ a $2,0 \mathrm{~Hz}$, no turno da tarde, entre zero a $-4,0 \mathrm{~Hz}$ e no turno da noite entre zero a $-7,0 \mathrm{~Hz}$, constatando uma resolução temporal mais fraca no turno da noite, onde a variação decresceu cerca de 2,0 a 3,0 Hz, quando comparadas às variações ocorridas nos turnos manhã e tarde.

Assim como RUSSEL (1961), MATSUMOTO et al (1978) afirmam, ocorre normalmente um declínio da freqüência crítica de fusão da luz após a realização de tarefas de fortes exigências mentais e essa diminuição é considerada como indício de fadiga mental.

Os referidos autores consideram o decréscimo nos resultados do Flicker um indicador de fadiga mental, uma vez que diante da complexidade do fenômeno ainda não foi possível encontrar um método objetivo totalmente fidedigno para expressar a fadiga mental, no entanto consideram a verificação de um decréscimo nos resultados de Flicker suficientemente capaz e adequado para verificar se um trabalho é fatigante ou não.

Comparando-se as diferenças entre as médias totais dos turnos manhã, tarde e noite, obteve-se que a diferença entre o inicio e o final do turno da manhã foi de $-2,0 \mathrm{~Hz}$, entre o início e o mal do turno da tarde foi de $-0,5 \mathrm{~Hz}$ e no turno da noite a diferença foi de $-1,4 \mathrm{~Hz}$.

Esses decréscimos do Flicker indicaram que as enfermeiras nos finais de cada turno apresentaram indícios de fadiga mental.

Outro indicador objetivo da fadiga mental utilizado foi a verificação do Tempo de Reação simples (TRs) a estímulo auditivo, cujos resultados são apresentados a seguir.

Figura 4- Distribuição das diferenças observadas na verificação do Tempo de Reação simples, segundo o período inicial e final dos turnos da manhã, trabalhados durante quinze dias por 12 enfermeiras, Ribeirão Preto - SP - Brasil

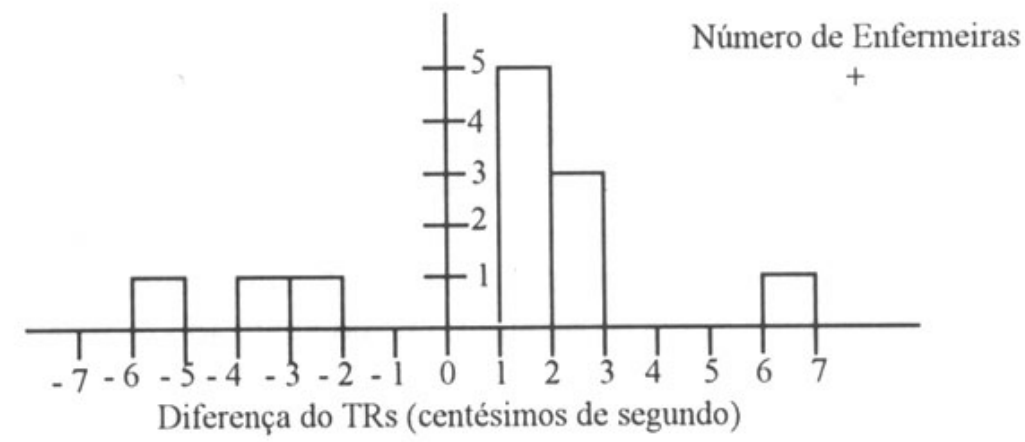


A figura 4 ilustra as variações ocorridas nos turnos da manhã. Observou-se que $75,0 \%$ das enfermeiras obtiveram diferenças entre o inicio e final dos turnos entre zero e 7,0 centésimos de segundo, enquanto $25,0 \%$ das enfermeiras obtiveram diferenças estabelecidas entre zero e -6,0 centésimos de segundo.

Segundo WILKINSON e HOUGHTON (1982), variáveis como motivação, interesse, expectativa, excitação, concentração e situação emocional podem influenciar significativamente na rapidez da resposta do tempo de reação.

Observa-se, na figura 4 que, no período da manhã, $16,6 \%$ das enfermeiras apresentaram intervalo do TRs estabelecido entre 2,0 e 4,0 centésimos de segundo. Quando analisadas as diferenças entre o início e final dos turnos, constatou-se que 8,3\% das enfermeiras obtiveram um TRs estabelecido entre 5,0 e 6,0 centésimos de segundo.

No entanto observou-se uma tendência de aumento no valor do tempo de reação simples no final do turno da manhã, sendo que $66,6 \%$ das enfermeiras aumentaram os valores do tempo de reação em cerca de 1,0 a 3,0 centésimos de segundos, 8,3\% das enfermeiras aumentaram cerca de 6,0 a 7,0 centésimos de segundo.

Figura 5 - Distribuição das diferenças individuais observadas na verificação do Tempo de Reação simples (TRs) em centésimos de segundo, relativos ao início e final dos turnos da tarde, trabalhadas durante quinze dias por 12 enfermeiras, Ribeirão Preto SP - Brasil

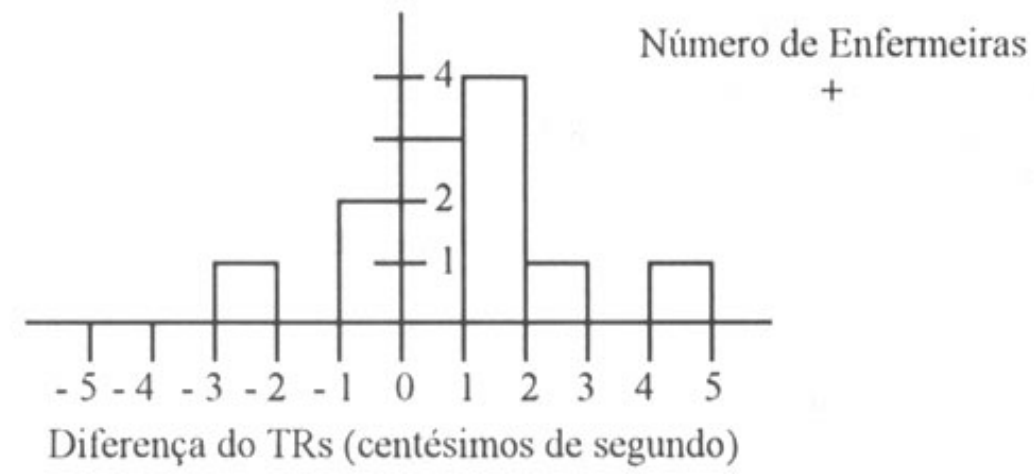

Observa-se na figura 5 que as variações do turno da tarde ocorreram entre $-3,0$ centésimos de segundo e 5,0 centésimos de segundo. Constatou-se que 75,0\% das enfermeiras gastaram mais tempo em emitir resposta quando observadas as diferenças das médias dos TRs emitidos no início e ao final dos turnos da tarde, o que indicou um significativo desgaste mental no turno analisado. 
Das referidas enfermeiras, 25,0\% demoraram cerca de 1,0 centésimo de segundo a mais na emissão de resposta ao estímulo no final do turno da tarde, quando comparado aos dados obtidos no início do turno, 33,3\% das enfermeiras demoraram cerca de 1,0 a 2,0 centésimos de segundo a mais para emissão da resposta, 8,3\% das enfermeiras demoraram cerca de 2,0 a 3,0 centésimos de segundo a mais e 8,3\% das enfermeiras demoraram cerca de 4,0 a 5,0 centésimos de segundo.

Figura 6 - Distribuição das diferenças observada na verificação do Tempo de Reação simples (TRs) em centésimos de segundo, relativos ao início e ao final dos turnos da noite, trabalhadas durante quinze dias por 12 enfermeiras, Ribeirão Preto - SP - Brasil

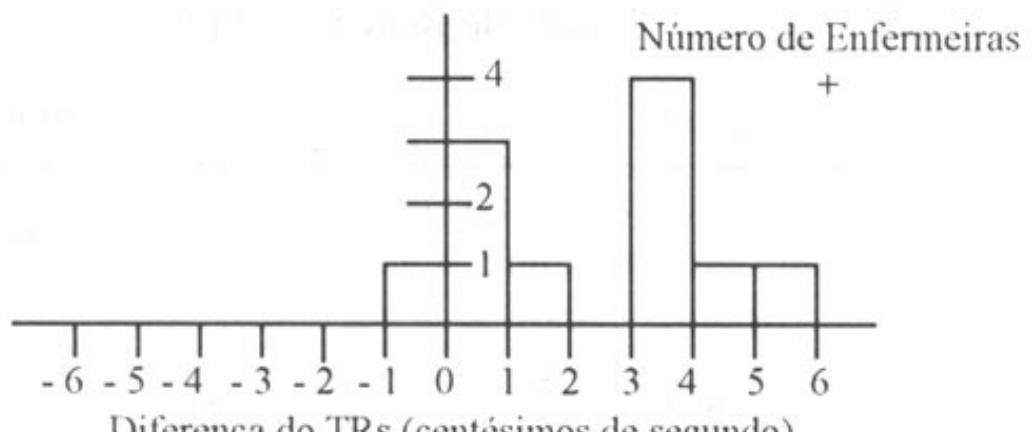

Diferença do TRs (centésimos de segundo)

No turno da noite os resultados da figura 6 indicaram que $83,3 \%$ das enfermeiras apresentaram acréscimo no tempo gasto para reagir ao estimulo auditivo, $25,0 \%$ das enfermeiras obtiveram acréscimo de 1,0 centésimo de segundo, 8,3\% de 1,0 a 2,0 centésimos de segundo, 33,3\% entre 3,0 a 4,0 centésimos de segundo e 8,3\% das enfermeiras apresentaram respectivamente acréscimos de 4,0 a 5,0 centésimos de segundos e 5,0 a 6,0 centésimos de segundo.

Apenas $16,6 \%$ das enfermeiras apresentaram decréscimos no TRs com valores entre zero e 1,0 centésimo de segundo.

Analisando-se as médias totais do TRs obtidas no início e final dos turnos, obteve-se os valores: manhã início $=22,0$ centésimos de segundo, e final $=23,1$ centésimos de segundo, tarde início = 21,3 centésimos de segundo, e final = 22,4 centésimos de segundo, noite inicio $=21,2$ centésimos de segundo, e final $=22,5$ centésimos de segundo.

Apesar dos valores do TR5 a estímulo auditivo descritos na literatura desde 1954 serem por volta de 0,14s.(WOODWORTH, 1964), e dos valores encontrados neste estudo serem maiores, existe uma tendência que indica um aumento do TRs no final da jornada de trabalho, o qual corrobora com os resultados obtidos no estudo realizado por WILKINSON et al (1989). 
Através do teste de Friedman (apud HOLLANDER e WOLFE, 1973), os dados obtidos no final dos turnos de trabalho, apesar de serem maiores que os encontrados no início do período, não apresentaram diferenças estatísticas significativas quando aplicado o teste quiquadrado ao nível de $\alpha=0,05$ como pode ser observado através da tabela 3 , a qual ilustra tal afirmação.

Tabela 3 - Distribuição da Estatística Observada através da aplicação do teste de Friedman em relação à verificação do tempo de reação simples a estímulo auditivo, segundo o período de trabalho durante os turnos trabalhados por 12 enfermeiras na segunda quinzena do mês de julho de 1989, Ribeirão Preto

\begin{tabular}{|c|c|c|c|}
\hline \multicolumn{4}{|c|}{ Tempo de Reação simples } \\
\hline & Início & & Fim \\
\hline Estatística Observada & 0,5 & & 0,6 \\
\hline Valor Tabelado & 5,99 & $(\alpha=0,05)$ & \\
\hline
\end{tabular}

Em relação ao número de erros obtidos pelas enfermeiras durante a aplicação do teste de TRs, observou-se, que o número de erros foi maior nos turnos da noite, seguido pelos turnos da manhã e tarde. Tais dados reforçam as afirmações já feitas: quanto mais fatigada a pessoa maior é a probabilidade de errar.

\section{CONCLUSÕES}

A diversidade das atividades desenvolvidas, as interrupções freqüentes do trabalho, os imprevistos e o lidar com o sofrimento e morte são aspectos agravantes no trabalho de enfermagem que conduzem ao desgaste mental.

O esquema de turnos alternantes influencia negativamente os horários reservados à alimentação, sono e repouso, o relacionamento com a família e amigos, a realização de atividades sociais e de lazer, além de ser considerado como fator interferente ao aparecimento de fadiga e motivo de insatisfação para maioria das enfermeiras. 
Sintomas subjetivos de fadiga relativos a inabilidade de concentração apresentaramse de maneira semelhante no início e final do turno, sintomas relativos a embotamento e distúrbios do sono foram mais apresentados ao final dos turnos obedecendo à ordem: turno da noite>manhã >tarde. Sintomas relativos ao padrão de desconforto físico foram mais apresentados no início dos turnos sendo: turno da noite>manhã>tarde. Sintomas opostos à sensação de fadiga foram apresentados mais no início e ao final dos turnos, na seguinte ordem: turno da tarde>noite>manhã.

Indícios objetivos de fadiga mental foram detectados, através do Flicker em 100,0\% das enfermeiras do turno da manhã, quando comparados os valores obtidos no inicio e término dos turnos. No turno da tarde indícios de fadiga mental foram apresentados por $66,4 \%$ das enfermeiras e no turno da noite, $100,0 \%$ das enfermeiras apresentaram indícios de fadiga mental.

Através da aferição do Tempo de Reação simples e estímulo auditivo 75,0\% das enfermeiras demonstraram indícios de fadiga noturno da manhã, 75,0\% no turno da tarde, e $83,3 \%$ no turno da noite.

Frente à inexistência atual de testes experimentais mais acurados para detecção e aferição da fadiga mental, considerou-se que a utilização da freqüência crítica de fusão da luz e do Tempo de Reação simples à estímulo auditivo foram eficientes para detecção de indícios objetivos de fadiga mental em esquema de turnos alternantes.

\section{SHIFT SCHEDULE: MENTAL FATIGUE IN NURSING}

The goal of the present study was to detect signs and symptoms of mental fatigue in nurses working in the hospital with shift schedule. The signs and symptoms of mental fatigue were measured by a subjective indicator, composed of a check list and two objective indicators called critical frequency of light fusion (Flicker), and Reaction Time to auditive stimulus (RTs). During fifteen consecutive days, morning, afternoon and night shifts of 12 nurses working in three different units of a university hospital were analyzed. The great rotation in work schedule, when in just one week a nurse can work up to three different shifts, is hazardous to the health, social, familiar and professional life of those nurses, who were not satisfied with the work schedule adopted by the institution and showed signs and symptoms of mental fatigue. The incidence of symptoms was greater for the night than for the morning shift which was greater than the afternoon shift and they frequently showed irritabilig and sleep disturbances. Indications of mental fatigue were detected by Flicker verification in the following order: morning shift greater than night shift which was greater than afternoon shift. On the other hand, using RTs the following indices of fatigue were detected: greater in the evening shift than morning shift which was greater than the afternoon shift.

UNITERMS: mental fatigue, shift schedule 


\section{TURNOS ALTERNANTES: FATIGA MENTAL EN ENFERMERÍA}

El objetivo del presente estudio fue detectar síntomas y señales de fatiga mental, en enfermeras actuantes en instituciones hospitalarias con esquema de trabajo en turnos alternantes, a través de un indicador subjetivo "check-list" y de los indicadores objetivos Frecuencia Crítica de Fusión de la luz (Flicker) y Tiempo de Reacción simple a estímulo auditivo (TRS) Fueron analizadas, 15 jornadas consecutivas trabajadas en los turnos mañana, tarde y noche por 12 enfermeras de tres unidades de internación diferentes de un hospital universitario. Los resultados sugieren que la alternancia existente entre los turnos es perjudicial a la salud y a la vida socio familiar y profesional de esas enfermeras, las cuales revelaron insatisfacción por el esquema de trabajo y presentaron síntomas y señales de fatiga mental. La incidencia de los síntomas fue mayor en la turno de la noche, si relacionado con el de la mañana, el cual por su vez, fue mayor que el de la tarde, comparados los valores del comiengo y del final de los turnos, evidenciándose con mayor frecuencia los síntomas de embotamiento y disturbios del sueño. Indicios de fatiga fueron detectados a través del Flicker en el siguiente orden: turno de la mañana mayor que el de la noche, siendo este último mayor que el de la tarde, cuando comparados los valores del comienzo y el final de los turnos. En contrapartida, en la verificación del tiempo de Reacción simple, los indicios de fatiga fueron presentados en el turno de la noche en frecuencia mayor que la del turno de la mañana, la cual fue mayor que la de la tarde.

UNITERMOS: fatiga mental, turnos alternantes

\section{REFERÊNCIAS BIBLIOGRÁFICAS}

01. AQUINO, E.M.L. et al. Saúde e trabalho de mulheres profissionais de enfermagem em um hospital público de Salvador - Bahia. Rev.Bras.Enfermagem, Brasília, v. 46, n. 3/4, p. 245-57, 1993.

02. CAMERON, C. Theory of fatigue. Ergonomics. v. 16, n. 5, p. 633-48, 1973.

03. CARVALHO, E.C. de. Comportamento verbal e enfermagem: a interação verbal enfermeiro paciente durante o procedimento de punção venosa. Ribeirão Preto, p. 110. Dissertação (Mestrado). Escola de Enfermagem de Ribeirão Preto Universidade de São Paulo, 1979.

04. CONSELHO FEDERAL DE ENFERMAGEWASSOCIAÇÂO BRASILEIRA DE ENFERMAGEM. A enfermagem nas instituições de saúde no Brasil. Rio de Janeiro: 1985.

05. COUTO, H.DE A. Fisiologia do trabalho aplicado. Belo Horizonte: IBERICA, 1978. p. 295. 
06. DESCHAMPS, D.; CREPY, M.N. Chronophysiologie et travail in horaries alternantes. Rev.De l'infirmiére, v. 6, p. 28-31, 1989.

07. DUMAZEDIER, I. Lazer e cultura popular. São Paulo: Perspectiva, 1973. p. 20-34.

08. ESPOSITO, I. et al. Repercussões da fadiga psíquica no trabalhador e na empresa.

Rev.Bras.Saúde Ocup., v. 8, n. 32, p. 37-45, 1980.

09. ESTRYN-BEHAR, M. Conditions de travail el dificultés socieles des femrnes travaillant à I'hospital. In: EQUILIBRE OU FATIGUE PAR LE TRAVAIL?. Paris, Societé Française de Psychologie du Travail: Éditions ESF, 1980. p. 141-51.

10. FISCHER, F.M. Acidentes de trabalho entre trabalhadores em turnos de indústria automobilística. Rev.Bras.Saúde Ocup., v. 52, n. 13, p. 34-59, 1985.

11. GENAILLE, V. Alimentation et personnel hospitalier de nuit. Rev.De I'infirmiére, v. 7, p. 30-2, 1990.

12. GOMES, D.L.S. Estudo dos riscos à saúde das pessoas que trabalham na enfermagem hospitalar. Rev.Paul.Enfermagem, v. 34, n. 517, p. 85-92, 1986.

13. HOLLANDER, M.; WOLFE, D.A. Nonparametric statistical methods. New York: John Willey, 1973.

14. LAURENTI, R. O problema das doenças crônicas e degenerativas e dos acidentes nas áreas urbanizadas da América Latina. Rev.Saúde Pública, v. 9, p. 239-48, 1975.

15. LOPES, M.J.M. O trabalho da enfermeira: nem público, nem privado, feminino, doméstico e desvalorizado. Rev.Bras.Enfermagem. Rio de Janeiro, v. 41, n. 3/4, p. 211-7, 1988.

16. MARZIALE, M.H.P. et al. A postura corporal adotada pela enfermeira durante a execução de seu trabalho. Rev.Bras.Saúde Ocup., São Paulo, v. 19, n. 13, p. 19-24, abril/junho, 1991.

17. MATSUMOTO, K. et al. Studies on fatigue of hospital nurses due to shift work. Jap.Ind.Health, v. 20, n. 2, p. 81-93, 1978.

18. MUELLER, C.G. Psicologia sensorial. Rio de Janeiro: Zahar, 1966.

19. POSSO, M.B.S. Fontes potenciais de riscos físicos e químicos: incidentes sobre os membros da equipe cirúrgica. São Paulo, p. 91. Tese (Doutorado) - Escola de Enfermagem de Ribeirão Preto - Universidade de São Paulo, 1988.

20. POTTLER, R.M., ESTRYN-BEHAR, M. L'Ergonomie en milieu hospitalier. Actes Dir XV Congres de la societé D’Ergonomie de Langue Française. Paris - France: 1979.

21. RUSSEL, A. Arbeits psychologie. Bem: Hans Huber, 1961. p. 215-21.

22. RUTENFRANZ, J. et al. Trabalhos em turno. Trad. Reinaldo Mestrinel. São Paulo: HICITEC, 1989. p. 135. 
23. WILKINSON, R.T.; HOUGTON, D. Fiel test arousal: a portable reaction timer with data storage, Human Factors, v. 24, p. 487-93, 1982.

24. WISNER, A. Por dentro do trabalho: método e técnica. Trad. Flora Maria Gomide Vezzá. São Paulo: FTD-Oboré, 1987.

25. WOODWORTH, R.S., SCHLESDERG, H. Experimental psichology. Trad. Nuria Cortado. 3 ed.. Buenos Aires: Dikoman; Editorial Universitária, 1964.

26. YOSHITAKE, $\mathrm{H}$. The characteristics patterns of subjective fatigue of subjective fatigue symptoms. Ergonomics, v. 21, n. 3, p. 231-3, 1978. 